\title{
Characteristics of injuries of young adult male basketball players
}

\author{
A - preparing concepts \\ $\mathrm{B}$ - formulating methods \\ $\mathrm{C}$ - conducting research \\ Agnieszka Magdalena Nowak ${ }^{\mathrm{B}-\mathrm{F}}$, Antoni Pytel ${ }^{\mathrm{A}-\mathrm{C}, \mathrm{E}}$, Bartosz $^{\mathrm{M}}$ Molik $^{\mathrm{C}, \mathrm{E}-\mathrm{F}}$, \\ Jolanta Marszałek ${ }^{\text {A-C,E-F }}$
}

$\mathrm{D}$ - processing results

E - interpretation and conclusions

$\mathrm{F}$ - editing the

final version

Jozef Pilsudski University of Physical Education

Abstract:

Introduction: Basketball is characterized by high intensity play and a lot of physical contact. Players are required to be well-trained physically in order to be able to face the dynamics, speed and variability of the game and the training loads to which they are exposed. Basketball is a sport that predisposes the athletes to musculoskeletal injuries. The aim of this study was to characterize the injuries experienced by young adult male basketball players.

Material and methods: Young adult male Polish basketball players from various clubs $(17 \pm 1.4$ years; $n=28 ; 47 \%)$ and amateur basketball players $(17 \pm 1.4$ years; $n=30 ; 53 \%)$ took part in this study. To assess the injuries of young basketball players, a survey consisting of 28 questions was used.

Results: The most common injuries were lower limb injuries (54\%), of which ankle injuries prevailed (ankle injuries were the most common injuries of all). Upper limb injuries accounted for $36 \%$ of all injuries. Of these, subluxations in finger joints occurred most often. Most often, injuries occurred during physical contact with another player (40\%). Despite an injury, the players either did not alter the length of their warm-up or they devoted more time to it. In terms of stretching before a training session or a match, differences between players training up to three times a week and players training four or more times per week were statistically significant $(\chi 2=8.926, \mathrm{p}=0.012, \mathrm{~V}=0.392)$.

Conclusions: Basketball is a sport that causes injuries. Basketball players mostly experience lower limb injuries.

Key words: $\quad$ injuries, basketball, adolescents, injury prevention, stretching

\section{Introduction}

Basketball is a very dynamic game combining elements of aerobic and anaerobic performance $[1,2]$. Modern basketball is characterised as a sport with frequent high-intensity efforts, with changes in the type of movement occurring every 1-2 seconds [3]. Basketball is a physical game where physical contact between players is expected and accepted. Players constantly use their bodies to gain advantage during the fight for a position or in the act of shooting, deliberately seeking contact with a defender and using their elbows and forearms to ward off their opponents [4,5]. Basketball players should demonstrate good dynamics and precision of movements, endurance and anticipation of situations that may happen on the court. The ability to accelerate quickly, slow down and change direction is an integral part of basketball and may vary depending on the position on the court [3]. 
There is no division into attackers and defenders in basketball. However, within the team, players can be divided into five positions: point guard (PG), shooting guard (SG), small forward (SF), power forward (PF) and center (C) [3]. These positional assignments are not fixed because it often happens that an athlete plays in two or even three positions in one game.

The dynamics, speed and changeability of the basketball game mean that to be well-prepared for it, players take part in training sessions that focus on improving power, speed, endurance and strength. Excessive training loads as well as the game itself may lead to injuries [6] and various overloadrelated stresses can cause overtraining syndromes, which affects players' performance [7] and impacts their ability to participate in training sessions and games $[4,5,8]$.

On the other hand, the physical contact between players in the air is particularly dangerous in contact sports like basketball is (e.g. during offensive situation on the opponent side) [9]. This contact often occurs during the fight for the ball while rebounding, shooting and when blocking shots. The main mechanisms of basketball injuries were falls to the floor and landing on an opponent's foot (classic ankle joint injuries) [10,11]. Additionally, changes in the direction of dribbling and contact/collision with the opponent mainly resulted in knee injuries, while contact with sports elements primarily caused finger injuries [10]. The most frequent injuries described in the literature include lower limb injuries such as ankle sprains, knee injuries $[4,5,8,10]$, low back pain $[4,12]$ and finger injuries [10]. According to López González et al. [10], the most common injuries in male and female amateur basketball players (8-34 years old) are ligament sprains (45.8\%), followed by bruises, dislocations/fractures and muscle-tendon injuries $(16.7 \%, 16.7 \%$ and $12.5 \%$, respectively) [10]. Pasanen et al. [8], who focused on ligament or joint injuries only, reported that these types of injuries accounted for $67 \%$ of all injuries in male and female adolescent players (12-18 years old) [8]. It was noted that none of the authors focused on different types of injuries in a group of young adult males (15-20 years old). Hence, the aim of the study was to characterize injuries in young adult male basketball players based on their knowledge.

\section{Material and methods}

Fifty-eight adolescent and young male Polish basketball players aged between 15 and $20( \pm 1.4)$ took part in this research $(\mathrm{n}=58)$. The study was conducted during the summer basketball camp. The players were divided according to the sports level represented. Twenty-eight study participants were professional players (club players), while 31 subjects played basketball only in the amateur league (amateur players). Coaches and players gave their informed consent to participate in the study. The characteristics of the study group are presented in Table 1 (Table 1).

Tab. 1. The characteristics of the study group divided into professional and amateur players

\begin{tabular}{|c|c|c|c|c|c|c|c|c|}
\hline \multirow[b]{2}{*}{ Parameters } & \multicolumn{4}{|c|}{ Club players $(n=28)$} & \multicolumn{4}{|c|}{ Amateur players $(n=30)$} \\
\hline & $\bar{x}$ & SD & Min & $\operatorname{Max}$ & & SD & Min & $\operatorname{Max}$ \\
\hline Age (years) & 17 & 1.4 & 15 & 20 & 17 & 1.4 & 16 & 20 \\
\hline Body height (cm) & 183 & 6.5 & 172 & 195 & 183 & 9.2 & 170 & 200 \\
\hline Body weight (kg) & 78 & 12.3 & 60 & 100 & 76 & 6.8 & 55 & 100 \\
\hline BMI (kg/) & 23.1 & 2.7 & 18.1 & 28.7 & 22.6 & 2.2 & 17.5 & 26.6 \\
\hline
\end{tabular}

$\bar{x}$ - mean; SD - standard deviation; Min - the smallest value; Max - the highest value; BMI - body mass index

An original questionnaire consisting of 28 questions was used. Questions 1-4 concerned anthropometric data of the players. Questions 5-9 referred to the number of training sessions per week, position on the court, type of surface for training/matches and game shoes. Questions 10-17 regarded injuries, i.e. the part of the body affected by the injury, the type of the injury, the cause and circumstances of the injury, the presence of the coach when the injury was sustained, reinjury occurrence, the consultation in relation to the injury, exclusion from training/matches, the type of treatment used. Questions 18-28 concerned an individual warm-up before and after the injury, stretching before and after training/matches, types of exercises used in an individual warm-up before and after the injury, post-exercise recovery, orthopaedic support, the impact of the injury on physical fitness and the types of activities during training, where the discomfort associated with the injury is noticeable. 
The following definition of an injury was adopted for the purposes of the study: sports injury is any damage of the body that happened to the participant during training or during the basketball match and made it difficult for him to play basketball for some time, i.e. the injury precluded the player from taking active part in training or matches [13].

\section{Statistical analysis}

Excel and IBM SPSS Statistics 24 were used for statistical analysis. The results are presented as numbers and percentages. In order to analyse the data, the research group was divided according to three criteria: 1. Club players and amateur players, 2. Training twice a week and more, 3. Playing on a surface adapted to basketball and playing on other types of floor. The answers to the questions obtained from the subgroups were compared. The chi-square test $(\chi 2)$ was used to check the dependence between the type of responses given and group affiliation. Statistical significance was assumed at the level of $\mathrm{p}<0.05$. In addition, Cramer's V was calculated.

\section{Results}

The study group consisted of 39 backcourt players and 19 frontcourt players. Just over $50 \%$ of the respondents declared that they played and trained on the surface adapted to basketball. Most of the respondents $(82 \%)$ experienced an injury of more than one part of the body. The most common injuries concerned lower limbs (54\%) and upper limbs $(36 \%)$. Among injuries of the lower limbs, ankle injuries prevailed (about 55\%), while among injuries of the upper limbs, finger injuries predominated (about 53\%). The most frequently declared cause of the injury was physical contact with another player. Over half of the respondents declared that they had experienced the same injury again. Detailed answers to selected questions from the questionnaire are presented in table 2 and table 3 .

Tab. 2. Answers to the questions related to the game and the injury experienced by the tested basketball players

\begin{tabular}{|c|c|c|c|}
\hline Question & Answer & Number of answers (N) & Percentage of answers (\%) \\
\hline \multirow{5}{*}{ How many times a week do you train? } & 1-2 times per week & 22 & $37.9 \%$ \\
\hline & 3-4 times per week & 25 & $43.1 \%$ \\
\hline & 5-6 times per week & 7 & $12.0 \%$ \\
\hline & 7 times per week & 4 & $6.8 \%$ \\
\hline & & $\mathrm{N}=58$ & $100.0 \%$ \\
\hline \multirow{5}{*}{ How often do you change sports shoes? } & Less often than once a season & 7 & $12.0 \%$ \\
\hline & Once a season & 33 & $56.8 \%$ \\
\hline & Twice a season & 16 & $27.6 \%$ \\
\hline & More than twice in the season & 2 & $3.4 \%$ \\
\hline & & $\mathrm{N}=58$ & $100.0 \%$ \\
\hline \multirow{7}{*}{ What part of your body was injured? } & Head & 3 & $3.0 \%$ \\
\hline & Chest & 0 & $0.0 \%$ \\
\hline & Back & 6 & $6.0 \%$ \\
\hline & Upper limb & 36 & $36.0 \%$ \\
\hline & Lower limb & 54 & $54.0 \%$ \\
\hline & Neck & 1 & $1.0 \%$ \\
\hline & & $\mathrm{N}=100$ & $100.0 \%$ \\
\hline \multirow{8}{*}{ What kind of an injury was it? } & Twist/ sprain & 39 & $33.9 \%$ \\
\hline & Dislocation & 21 & $18.3 \%$ \\
\hline & Rupture & 5 & $4.4 \%$ \\
\hline & Break/ fracture & 15 & $13.0 \%$ \\
\hline & Contusion/Bruises & 16 & $13.9 \%$ \\
\hline & Strain & 13 & $11.3 \%$ \\
\hline & Other & 6 & $5.2 \%$ \\
\hline & & $\mathrm{N}=115$ & $100.0 \%$ \\
\hline
\end{tabular}




\begin{tabular}{|c|c|c|c|}
\hline & Physical contact with another player & 36 & $40.4 \%$ \\
\hline & Jumping & 6 & $6.7 \%$ \\
\hline & Landing & 8 & $9.0 \%$ \\
\hline & Changing direction & 1 & $1.1 \%$ \\
\hline \multirow[t]{6}{*}{ How did the injury occur? } & Contact with the ball & 16 & $18.0 \%$ \\
\hline & Running & 4 & $4.5 \%$ \\
\hline & Falling down & 3 & $3.4 \%$ \\
\hline & Overload & 15 & $16.9 \%$ \\
\hline & & $\mathrm{N}=89$ & $100.0 \%$ \\
\hline & During a training session & 34 & $45.3 \%$ \\
\hline \multirow[t]{2}{*}{ When did the injury occur? } & During a match & 41 & $54.7 \%$ \\
\hline & & $\mathrm{N}=75$ & $100.0 \%$ \\
\hline
\end{tabular}

Tab. 3. Answers to the questions related to the consequences of injuries and preventive actions taken by the surveyed basketball players

\begin{tabular}{|c|c|c|c|}
\hline Question & Answer & Number of answers (N) & Percentage of answers $(\%)$ \\
\hline \multirow{3}{*}{ Have you had the same injury again? } & Yes & 31 & $53.4 \%$ \\
\hline & No & 27 & $46.6 \%$ \\
\hline & & $\mathrm{N}=58$ & $100.0 \%$ \\
\hline \multirow{5}{*}{$\begin{array}{l}\text { How many average training days did you lose due } \\
\text { to the injury? }\end{array}$} & $<1$ week & 13 & $22.4 \%$ \\
\hline & 1-2 weeks & 16 & $27.6 \%$ \\
\hline & 3-4 weeks & 14 & $24.1 \%$ \\
\hline & $>4$ weeks & 15 & $25.9 \%$ \\
\hline & & $\mathrm{N}=58$ & $100.0 \%$ \\
\hline \multirow{5}{*}{$\begin{array}{l}\text { How much time did you spend performing } \\
\text { an individual warm-up before the injury? }\end{array}$} & Up to 10 minutes & 28 & $48.3 \%$ \\
\hline & 10-20 minutes & 24 & $41.4 \%$ \\
\hline & 20-30 minutes & 5 & $8.6 \%$ \\
\hline & Over 30 minutes & 1 & $1.7 \%$ \\
\hline & & $\mathrm{N}=58$ & $100.0 \%$ \\
\hline \multirow{4}{*}{ Is your warm-up longer or shorter after the injury? } & Longer & 29 & $50.0 \%$ \\
\hline & Shorter & 3 & $5.2 \%$ \\
\hline & No change & 26 & $44.8 \%$ \\
\hline & & $\mathrm{N}=58$ & $100.0 \%$ \\
\hline \multirow{4}{*}{$\begin{array}{l}\text { Do you do stretching exercises before training } \\
\text { sessions or matches? }\end{array}$} & Yes, always & 35 & $60.3 \%$ \\
\hline & Yes, rarely & 17 & $29.3 \%$ \\
\hline & No & 6 & $10.3 \%$ \\
\hline & & $\mathrm{N}=58$ & $100.0 \%$ \\
\hline \multirow{4}{*}{ Do you stretch after sports activities? } & Yes, always & 18 & $31.0 \%$ \\
\hline & Yes, rarely & 29 & $50.0 \%$ \\
\hline & No & 11 & $19.0 \%$ \\
\hline & & $\mathrm{N}=58$ & $100.0 \%$ \\
\hline \multirow{3}{*}{ Do you use any post-exercise recovery strategies? } & Yes & 36 & $62.1 \%$ \\
\hline & No & 22 & $37.9 \%$ \\
\hline & & $\mathrm{N}=58$ & $100.0 \%$ \\
\hline
\end{tabular}

Most often, players did an individual warm-up for up to 10 minutes or 10-20 minutes. After the first injury, $50 \%$ of the respondents lengthened their individual warm-up time, whereas $44.8 \%$ of the respondents did not change it. Most players $(89.6 \%)$ declared that they do stretching exercises before matches or training sessions. Also, most respondents (81\%) thought that stretching exercises after sports activities are needed. Such exercises were always done by every third person and were rarely done by every second person (Tab.3).
Figure 1 shows the types of exercises performed by the players during an individual warm-up before and after the injury occurred. The most commonly used exercises prior to sustaining the injury were running, static stretching and ball exercises $(24 \%, 23 \%$ and $21 \%$, respectively). After the injury, such activities included running, static stretching and dynamic stretching (24\%, 22\% and 21\%, respectively) (Fig. 1). Tables 4, 5 and 6 present the relationships between the types of answers to the questions in the questionnaire and affiliation to one of the three subgroups examined 
(Tab. 4, Tab. 5, Tab. 6). The differences regarding stretching exercises performed before training sessions or matches between the players training up to three times a week and those training four or more times a week were statistically significant $(\chi 2=8.926$, $\mathrm{p}=0.012, \mathrm{~V}=0.392)($ Tab. 5).

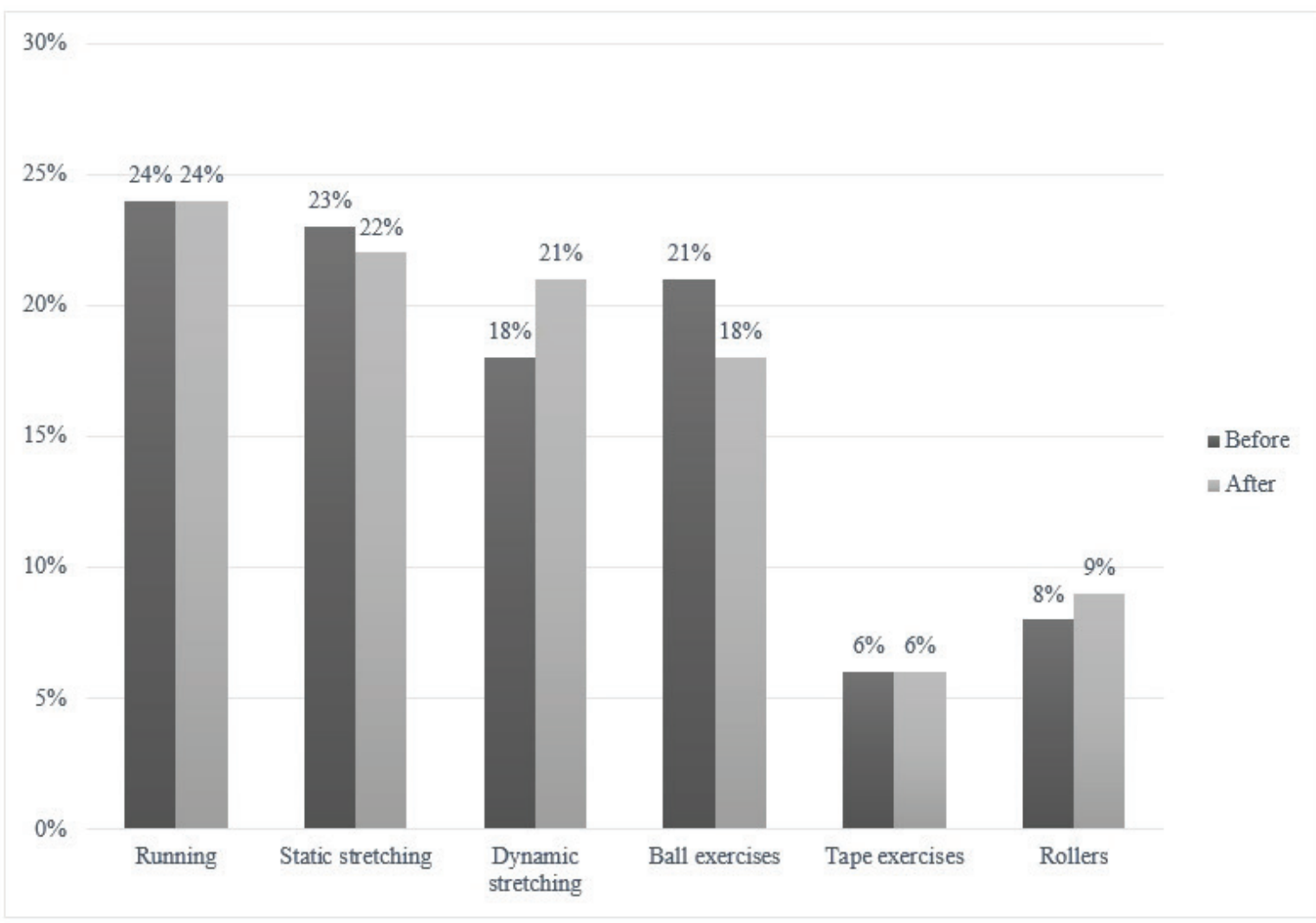

Fig. 1. Types of exercises performed during an individual warm-up before and after the injury in young basketball players

Tab. 4. Differences in answers to the questions between club players and amateur players

\begin{tabular}{|c|c|c|c|c|c|}
\hline & Club players $(n=28)$ & $\begin{array}{l}\text { Amateur players } \\
\qquad(\mathrm{n}=30)\end{array}$ & $\chi^{2}$ & $\mathrm{p}$ & Cramer's V \\
\hline \multicolumn{6}{|l|}{ Do you attend additional sports activities? } \\
\hline Yes & $7(25 \%)$ & $6(20 \%)$ & 0.208 & 0.648 & 0.060 \\
\hline No & $21(75 \%)$ & $24(80 \%)$ & & & \\
\hline \multicolumn{6}{|l|}{ How often do you change sports shoes? } \\
\hline Less often than once a season & $3(11 \%)$ & $4(14 \%)$ & & & \\
\hline Once a season & $14(50 \%)$ & $19(63 \%)$ & 3.085 & 0.379 & 0.231 \\
\hline Twice a season & $9(32 \%)$ & $7(23 \%)$ & & & \\
\hline More than twice in the season & $2(7 \%)$ & $0(0 \%)$ & & & \\
\hline \multicolumn{6}{|l|}{$\begin{array}{l}\text { How many average training days did you lose due to the } \\
\text { injury? }\end{array}$} \\
\hline 0 days & $0(0 \%)$ & $1(3 \%)$ & & & \\
\hline Up to 7 days & $6(22 \%)$ & $7(23 \%)$ & 6.921 & 0.140 & 0.345 \\
\hline Up to 14 days & $7(25 \%)$ & $8(27 \%)$ & & & \\
\hline Up to 30 days & $4(14 \%)$ & $10(33 \%)$ & & & \\
\hline Over 30 days & $11(39 \%)$ & $4(14 \%)$ & & & \\
\hline \multicolumn{6}{|l|}{ What kind of treatment did you have? } \\
\hline I treated the injury myself & $6(21 \%)$ & $13(43 \%)$ & 3.155 & 0.076 & 0.233 \\
\hline I was treated by a physiotherapist & $22(79 \%)$ & $17(57 \%)$ & & & \\
\hline
\end{tabular}




\begin{tabular}{|c|c|c|c|c|c|}
\hline \multicolumn{6}{|l|}{$\begin{array}{l}\text { How much time did you spend performing an individual } \\
\text { warm-up before the injury? }\end{array}$} \\
\hline Up to 10 minutes & $12(43 \%)$ & $16(53 \%)$ & \multirow{4}{*}{1.871} & \multirow{4}{*}{0.600} & \multirow{4}{*}{0.180} \\
\hline 10-20 minutes & $13(46 \%)$ & $11(37 \%)$ & & & \\
\hline 20-30 minutes & $3(11 \%)$ & $2(7 \%)$ & & & \\
\hline Over 30 minutes & $0(0 \%)$ & $1(3 \%)$ & & & \\
\hline \multicolumn{6}{|l|}{ Is your warm-up longer or shorter after the injury? } \\
\hline Longer & $12(43 \%)$ & $17(57 \%)$ & \multirow{3}{*}{1.744} & \multirow{3}{*}{0.418} & \multirow{3}{*}{0.173} \\
\hline Shorter & $1(4 \%)$ & $2(6 \%)$ & & & \\
\hline No change & $15(53 \%)$ & $11(37 \%)$ & & & \\
\hline \multicolumn{6}{|l|}{$\begin{array}{l}\text { Do you do stretching exercises before training sessions or } \\
\text { matches? }\end{array}$} \\
\hline Yes, always & $19(68 \%)$ & $16(53 \%)$ & \multirow[t]{3}{*}{2.917} & \multirow[t]{3}{*}{0.233} & \multirow[t]{3}{*}{0.224} \\
\hline Yes, rarely & $8(28 \%)$ & $9(30 \%)$ & & & \\
\hline No & $1(4 \%)$ & $5(17 \%)$ & & & \\
\hline \multicolumn{6}{|l|}{ Do you think stretching after sports activities is needed? } \\
\hline Yes & $22(79 \%)$ & $25(83 \%)$ & \multirow[t]{2}{*}{0.214} & \multirow[t]{2}{*}{0.644} & \multirow[t]{2}{*}{0.061} \\
\hline No & $6(21 \%)$ & $5(17 \%)$ & & & \\
\hline \multicolumn{6}{|l|}{ Do you stretch after sports activities? } \\
\hline Yes, always & $7(25 \%)$ & $11(37 \%)$ & \multirow{3}{*}{1.534} & \multirow{3}{*}{0.464} & \multirow{3}{*}{0.164} \\
\hline Yes, rarely & $16(57 \%)$ & $13(43 \%)$ & & & \\
\hline No & $5(18 \%)$ & $6(20 \%)$ & & & \\
\hline \multicolumn{6}{|l|}{ Do you use any post-exercise recovery strategies? } \\
\hline Yes & $12(43 \%)$ & $10(33 \%)$ & \multirow[t]{2}{*}{0.558} & \multirow[t]{2}{*}{0.455} & \multirow[t]{2}{*}{0.098} \\
\hline No & $16(57 \%)$ & $20(67 \%)$ & & & \\
\hline \multicolumn{6}{|l|}{ Do you use orthopaedic support during the game? } \\
\hline Yes & $7(25 \%)$ & $10(33 \%)$ & \multirow[t]{2}{*}{0.485} & \multirow[t]{2}{*}{0.486} & \multirow[t]{2}{*}{0.091} \\
\hline No & $21(75 \%)$ & $20(67 \%)$ & & & \\
\hline \multicolumn{6}{|l|}{$\begin{array}{l}\text { Do you think that the injury you experienced reduced your } \\
\text { fitness? }\end{array}$} \\
\hline Yes & $17(61 \%)$ & $21(70 \%)$ & \multirow[t]{2}{*}{0.317} & \multirow[t]{2}{*}{0.574} & \multirow[t]{2}{*}{0.075} \\
\hline No & $11(39 \%)$ & $9(30 \%)$ & & & \\
\hline
\end{tabular}

$* \mathrm{p}<0.05$

Tab. 5. Differences in answers to the questions between players training up to 3 times a week and 4 or more times a week

\begin{tabular}{|c|c|c|c|c|c|}
\hline & $\begin{array}{l}\text { Players training up to } \\
3 \text { times a week }(n=22)\end{array}$ & $\begin{array}{l}\text { Players training more } \\
\text { than } 3 \text { times a week } \\
\qquad(n=36)\end{array}$ & $\chi^{2}$ & $\mathrm{p}$ & Cramer's V \\
\hline \multicolumn{6}{|l|}{ Do you attend additional sports activities? } \\
\hline Yes & $7(32 \%)$ & $6(7 \%)$ & 1.803 & 0.179 & 0.176 \\
\hline No & $15(68 \%)$ & $30(83 \%)$ & & & \\
\hline \multicolumn{6}{|l|}{ How often do you change sports shoes? } \\
\hline Less often than once a season & $3(14 \%)$ & $4(11 \%)$ & & & \\
\hline Once a season & $15(68 \%)$ & $18(50 \%)$ & 3.224 & 0.358 & 0.236 \\
\hline Twice a season & $4(18 \%)$ & $12(33 \%)$ & & & \\
\hline More than twice in the season & $0(0 \%)$ & $2(6 \%)$ & & & \\
\hline \multicolumn{6}{|l|}{ How many average training days did you lose due to the injury? } \\
\hline 0 days & $0(0 \%)$ & $1(3 \%)$ & \multirow{5}{*}{1.660} & \multirow{5}{*}{0.798} & \multirow{5}{*}{0.169} \\
\hline Up to 7 days & $4(18 \%)$ & $9(25 \%)$ & & & \\
\hline Up to 14 days & $7(32 \%)$ & $8(22 \%)$ & & & \\
\hline Up to 30 days & $6(27 \%)$ & $8(22 \%)$ & & & \\
\hline Over 30 days & $5(23 \%)$ & $10(28 \%)$ & & & \\
\hline
\end{tabular}




\begin{tabular}{|c|c|c|c|c|c|}
\hline \multicolumn{6}{|l|}{ What kind of treatment did you have? } \\
\hline I treated the injury myself & $7(32 \%)$ & $12(33 \%)$ & 0.014 & 0.905 & 0.016 \\
\hline I was treated by a physiotherapist & $15(68 \%)$ & $24(67 \%)$ & & & \\
\hline \multicolumn{6}{|l|}{$\begin{array}{l}\text { How much time did you spend performing an individual warm- } \\
\text { up before the injury? }\end{array}$} \\
\hline Up to 10 minutes & $14(64 \%)$ & $14(39 \%)$ & 3809 & 0283 & 0256 \\
\hline 10-20 minutes & $7(32 \%)$ & $17(47 \%)$ & 5.009 & 0.205 & 0.250 \\
\hline 20-30 minutes & $1(4 \%)$ & $4(11 \%)$ & & & \\
\hline Over 30 minutes & $0(0 \%)$ & $1(3 \%)$ & & & \\
\hline \multicolumn{6}{|l|}{ Is your warm-up longer or shorter after the injury? } \\
\hline Longer & $10(46 \%)$ & $19(53 \%)$ & 0385 & 0825 & 0081 \\
\hline Shorter & $1(4 \%)$ & $2(6 \%)$ & 0.585 & 0.825 & 0.081 \\
\hline No change & $11(50 \%)$ & $15(41 \%)$ & & & \\
\hline \multicolumn{6}{|l|}{$\begin{array}{l}\text { Do you do stretching exercises before training sessions or } \\
\text { matches? }\end{array}$} \\
\hline Yes, always & $8(36 \%)$ & $27(75 \%)$ & 8.926 & $0.012 *$ & 0.392 \\
\hline Yes, rarely & $11(50 \%)$ & $6(17 \%)$ & & & \\
\hline${ }_{-}$ & $3(14 \%)$ & $3(8 \%)$ & & & \\
\hline \multicolumn{6}{|l|}{ Do you think stretching after sports activities is needed? } \\
\hline 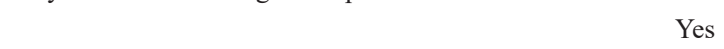 & $19(86 \%)$ & $28(78 \%)$ & 0.655 & 0.418 & 0.106 \\
\hline No & $3(14 \%)$ & $8(22 \%)$ & & & \\
\hline \multicolumn{6}{|l|}{ Do you stretch after sports activities? } \\
\hline Yes, always & $7(32 \%)$ & $11(31 \%)$ & 0029 & 0985 & 0023 \\
\hline Yes, rarely & $11(50 \%)$ & $18(50 \%)$ & 0.029 & 0.985 & 0.023 \\
\hline No & $4(18 \%)$ & $7(19 \%)$ & & & \\
\hline \multicolumn{6}{|l|}{ Do you use any post-exercise recovery strategies? } \\
\hline Yes & $8(36 \%)$ & $14(39 \%)$ & 0.037 & 0.847 & 0.025 \\
\hline No & $14(64 \%)$ & $22(61 \%)$ & & & \\
\hline \multicolumn{6}{|l|}{ Do you use orthopaedic support during the game? } \\
\hline 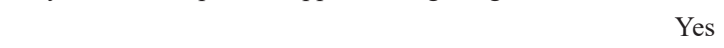 & $6(27 \%)$ & $11(31 \%)$ & 0.071 & 0.790 & 0.035 \\
\hline $\begin{array}{ll}2 & \text { No } \\
\end{array}$ & $16(73 \%)$ & $25(69 \%)$ & & & \\
\hline \multicolumn{6}{|l|}{$\begin{array}{l}\text { Do you think that the injury you experienced reduced your } \\
\text { fitness? }\end{array}$} \\
\hline $\begin{array}{l}\text { ntness? } \\
\end{array}$ & $13(59 \%)$ & $25(69 \%)$ & 0.925 & 0.336 & 0.127 \\
\hline No & $9(41 \%)$ & $11(31 \%)$ & & & \\
\hline
\end{tabular}

$* \mathrm{p}<0.05$

Tab. 6. Differences in answers to the questions between athletes playing on the surface adapted to basketball and other surfaces

\begin{tabular}{|c|c|c|c|c|c|}
\hline & $\begin{array}{l}\text { Playing on the adapted } \\
\text { surface }(n=34)\end{array}$ & $\begin{array}{c}\text { Playing on } \\
\text { a different surface } \\
(\mathrm{n}=24)\end{array}$ & $\chi^{2}$ & $\mathrm{p}$ & Cramer's V \\
\hline \multicolumn{6}{|l|}{ Do you attend additional sports activities? } \\
\hline Yes & $8(24 \%)$ & $5(21 \%)$ & 0.059 & 0.808 & 0.032 \\
\hline No & $26(76 \%)$ & $19(79 \%)$ & & & \\
\hline \multicolumn{6}{|l|}{ How often do you change sports shoes? } \\
\hline Less often than once a season & $5(15 \%)$ & $2(8 \%)$ & & & \\
\hline Once a season & $18(53 \%)$ & $15(63 \%)$ & 2.148 & 0.542 & 0.192 \\
\hline Twice a season & $9(26 \%)$ & $7(29 \%)$ & & & \\
\hline More than twice in the season & $2(6 \%)$ & $0(0 \%)$ & & & \\
\hline \multicolumn{6}{|l|}{ How many average training days did you lose due to the injury? } \\
\hline 0 days & $0(0 \%)$ & $1(4 \%)$ & \multirow{5}{*}{8.010} & \multirow{5}{*}{0.091} & \multirow{5}{*}{0.372} \\
\hline Up to 7 days & $7(20 \%)$ & $6(25 \%)$ & & & \\
\hline Up to 14 days & $8(24 \%)$ & $7(29 \%)$ & & & \\
\hline Up to 30 days & $6(18 \%)$ & $8(34 \%)$ & & & \\
\hline Over 30 days & $13(38 \%)$ & $2(8 \%)$ & & & \\
\hline
\end{tabular}




\begin{tabular}{|c|c|c|c|c|c|}
\hline \multicolumn{6}{|l|}{ What kind of treatment did you have? } \\
\hline I treated the injury myself & $10(29 \%)$ & $9(37 \%)$ & 0.418 & 0.518 & 0.085 \\
\hline I was treated by a physiotherapist & $24(71 \%)$ & $15(63 \%)$ & & & \\
\hline \multicolumn{6}{|l|}{$\begin{array}{l}\text { How much time did you spend performing an individual } \\
\text { warm-up before the injury? }\end{array}$} \\
\hline Up to 10 minutes & $15(44 \%)$ & $13(54 \%)$ & \multirow{4}{*}{2.802} & \multirow{4}{*}{0.423} & \multirow{4}{*}{0.220} \\
\hline 10-20 minutes & $15(44 \%)$ & $9(38 \%)$ & & & \\
\hline 20-30 minutes & $4(12 \%)$ & $1(4 \%)$ & & & \\
\hline Over 30 minutes & $0(0 \%)$ & $1(4 \%)$ & & & \\
\hline \multicolumn{6}{|l|}{ Is your warm-up longer or shorter after the injury? } \\
\hline Longer & $17(50 \%)$ & $12(50 \%)$ & \multirow{3}{*}{0.882} & \multirow{3}{*}{0.643} & \multirow{3}{*}{0.123} \\
\hline Shorter & $1(3 \%)$ & $2(8 \%)$ & & & \\
\hline No change & $16(47 \%)$ & $10(42 \%)$ & & & \\
\hline \multicolumn{6}{|l|}{$\begin{array}{l}\text { Do you do stretching exercises before training sessions } \\
\text { or matches? }\end{array}$} \\
\hline Yes, always & $23(68 \%)$ & $12(50 \%)$ & 5.080 & 0.079 & 0.296 \\
\hline Yes, rarely & $10(29 \%)$ & $7(29 \%)$ & & & \\
\hline No & $1(3 \%)$ & $5(21 \%)$ & & & \\
\hline \multicolumn{6}{|l|}{ Do you think stretching after sports activities is needed? } \\
\hline Yes & $28(82 \%)$ & $19(79 \%)$ & 0.093 & 0.760 & 0.040 \\
\hline No & $6(18 \%)$ & $5(21 \%)$ & & & \\
\hline \multicolumn{6}{|l|}{ Do you stretch after sports activities? } \\
\hline Yes, always & $10(29 \%)$ & $8(33 \%)$ & \multirow{3}{*}{0.494} & \multirow{3}{*}{0.781} & \multirow{3}{*}{0.093} \\
\hline Yes, rarely & $18(53 \%)$ & $11(46 \%)$ & & & \\
\hline No & $6(18 \%)$ & $5(21 \%)$ & & & \\
\hline \multicolumn{6}{|l|}{ Do you use any post-exercise recovery strategies? } \\
\hline Yes & $13(38 \%)$ & $9(37 \%)$ & 0.003 & 0.955 & 0.007 \\
\hline No & $21(62 \%)$ & $15(63 \%)$ & & & \\
\hline \multicolumn{6}{|l|}{ Do you use orthopaedic support during the game? } \\
\hline Yes & $8(24 \%)$ & $9(3 \%)$ & 1.325 & 0.250 & 0.151 \\
\hline No & $26(76 \%)$ & $15(63 \%)$ & & & \\
\hline \multicolumn{6}{|l|}{$\begin{array}{l}\text { Do you think that the injury you experienced reduced your } \\
\text { fitness? }\end{array}$} \\
\hline 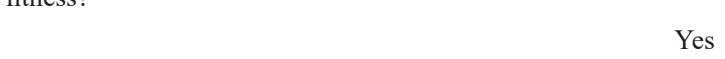 & $21(62 \%)$ & $17(71 \%)$ & 0.324 & 0.569 & 0.075 \\
\hline No & $13(38 \%)$ & $7(29 \%)$ & & & \\
\hline
\end{tabular}

$* \mathrm{p}<0.05$

\section{Discussion}

The purpose of this study was to characterize injuries in youth basketball based on the knowledge of young players.

The most frequent injuries received by young basketball players were lower limb injuries (54\%), including ankle sprains $(33.9 \%)$, while $53 \%$ of the respondents experienced the same type of the injury again. The most common injury was ankle joint injury. The results of this research are reflected in the reports of other scientists $[4,5,8,9,10,14,15]$. The most common situation in which the injury occurred was physical contact with another player, mainly in the offensive action (40\%). Other researchers indicated that lower limb injuries most often occurred when landing (after a jump) on an uneven surface, e.g. on the foot of another player
$[4,5,10,11,16]$ and during changes in the direction of dribbling (49\%) [9,10]. In the current study, the participants were asked about injuries picked up at the time of landing and injuries caused by physical contact with another player; however, they were not asked if physical contact occurred when jumping, landing or in other situations. Previous studies confirmed that injuries in adults were more frequent during matches than training sessions $[5,16]$. Additionally, there were studies that indicated more frequent injuries in adolescents during training sessions [8,10]. Meeuwisse et al. [5] and Dick et al. [16] examined adult basketball players $[5,16]$. López González et al. [10] studied individuals aged 8-34 [10], while Pasanen et al. focused on players aged $14.8( \pm 1.5)[8]$.

McKay et al. [11] studied professional and amateur basketball players in terms of assessing 
factors affecting an increased number of ankle sprains. It was noted that after an ankle injury, a player was 5 times more likely to have another injury of the same joint. As many as $45 \%$ of reinjuries occurred when the player landed on the foot of another player and it was the most common mechanism of ankle injury. In the literature, no statistically significant differences were found between injured and non-injured players in terms of age, body weight, body height, warm-up applied before the game, player position on the court and the price of shoes in which the athletes played [13]. Meeuwisse et al. [5] emphasized a higher probability of a reinjury after a primary injury of the same body area [5]. McKay et al. [11] observed that players using basketball shoes with an airbag under the heel (Air technology) experienced 4.3 times more frequent ankle injuries than those using shoes without air system [11]. Therefore, in the context of injury prevention, it may be recommended to pay attention to the construction of the soles in game shoes.

It is important to consider a possibility of minimizing the frequency of ankle sprains. One of the universal methods to protect against re-injury is the ankle stabilizer. In the study group, $25.4 \%$ of the players used orthopaedic support during the game. A study conducted by McGuine et al. [17] shows that wearing a tied stabilizer while playing basketball decreases the number of injuries but does not affect the severity of the damage if this injury happens [17]. There was also a trend toward ankle tape decreasing the risk of ankle injury in players with a history of ankle injury [11]. Another scientific report indicated that elite players generally wear mid- or high-top sneakers (designed to protect the ankle) and tape their ankles or wear braces [4]. For years, the basketball environment has been convinced that shoes reaching above the ankle joint prevent twisting of the ankle. In his research, Bishop showed that there were no statistically significant differences in inversion of the foot in a shoe with a high or low top [18]. Barrett et al. [19] indicated that there were no significant differences between the groups wearing low and high shoes while playing basketball when it came to injury incidence and severity [19]. Other researchers observed that despite wearing stabilizers or high-top shoes, players quite often experienced ankle injuries and it was advisable to conduct clinical and biomechanical studies to improve protection with a shoe and ankle-based equipment [4]. In the prevention of ankle injuries in sport, proprioceptive training is often used. Riva et al. [12] demonstrated that deep proprioceptive training involving exercises on unstable surfaces and single limb stance with closed eyes reduced the risk of ankle injuries by as much as $81 \%$ during the 6 years of study duration [12]. Eils et al. [20] undertook to develop an ankle injury prevention program, based on deep proprioception, and achieved a $65 \%$ reduction in the injuries of this joint and improvement in foot position sense [14]. Bonato et al. [21] conducted a warm-up based on neuromuscular training of their own body weight and obtained a significant reduction in lower limb injuries in female elite basketball players [21].

In the current study, it was observed that the differences between players training up to three times a week in terms of stretching before training sessions or matches were statistically significant $(\chi 2=8.926, p=0.012, \mathrm{~V}=0.392)$. These groups are different, and one would suppose that doing stretching exercises before sports activities may be an important factor in the prevention of injuries. During an individual warm-up, over $90 \%$ of the respondents declared that they performed a set consisting of the exercises shown in Fig. 1. The influence of stretching on injuries in athletes was often studied in the literature. Positive effects of dynamic stretching on the maximum jump and negative effects of static stretching were demonstrated $[22,23]$. It was proved that players who did not perform stretching exercises before the match were 2.6 times more likely to sustain ankle injuries [11]. On the other hand, the results from studies by Herman et al. [24] showed that a sport-specific warm-up consisting of stretching, balance exercises and agility exercises repeated over a three-month period may reduce the number of lower limb injuries [24]. Other researchers showed that adequate muscle length is particularly important in sports in which athletes use muscle work in a stretch-shortening cycle. It was proved that ensuring proper muscle stretching can protect athletes against injuries of the musculoskeletal units $[25,26]$. Subsequent studies assessed the effects of neuromuscular training on the risk of injuries. Gilchrist et al. [27] introduced a training program performed three times a week that included a warmup, plyometric exercises and agility exercises for football players. The authors observed a reduction in non-contact anterior cruciate ligament (ACL) 
injuries in the study group [27]. Emery et al. [28] and Riva et al. [12] used training on unstable surfaces to improve the balance of basketball players, thus achieving a reduction in injuries in this group $[12,28]$. When it comes to injury prevention training, it is also useful to learn the technique of correct movement. Hewett [29] introduced a 6-week training program for female athletes from American college sports associations. During this program, the players learned the correct jumping and landing technique. It turned out that thanks to the program, the players experienced fewer knee injuries [29].

In the case of the correlation between the quantity of training sessions a week and the number of injuries, it can be suspected that the higher the number of sessions a week, the greater the risk of injury and strain of the body, especially in youth sports, when the musculoskeletal system is just developing. In the current study, no correlations were found between the answers to the questions about behavioural changes related to the injury experienced or post-exercise recovery in terms of the frequency of playing basketball in a week. Caparrós et al. [30], who analysed data regarding the Spanish top professional league for seven years, noted a strong correlation between the number of training sessions, matches and time spent on the court in terms of the number of injuries among players [30]. In the present research, the respondents were neither adults nor experienced players from the highest national league, and slightly more than half of them (51.7\%) played basketball as amateurs.

According to our own observations and the literature, injuries can exclude players from training for a long time $[4,5,8,11]$ and serious injuries sometimes force them to end their careers $[4,5]$. Therefore, injury prevention is so important. In youth sport, coaches do not usually have time or proper training facilities (place and equipment for training) to implement measures to prevent injuries. They focus on technical skills and fitness preparation. Often, coaches of children and adolescents are young and inexperienced, and they do not have adequate knowledge in the field of injury prevention and training planning to allocate time resources to injury prevention. Preparing a player for hard training in professional sport is even more important. One of the ideas that could help basketball coaches to prevent injuries could be to implement ready-made standardized training developed by specialists. No scientific reports were found on this subject, but one can be inspired by FIFA 11+ program performed by the International Federation of Association Football (FIFA) [31]. Another program created for football that can also help players of various other sports is a program aimed at knee ligament injury prevention (Prevent injury and Enhance Performance - PEP). It consists of five parts such as a running warmup, strengthening exercises, plyometric exercises, agility exercises and stretching [32].

The above reports indicated a positive impact of FIFA $11+$ or PEP programs. Therefore, it would be reasonable to create a preventive program for young basketball players as well. This would facilitate coaches' work and reduce the number of injuries in basketball. Education of young basketball players is important in relation to injury prevention and how to deal with them. Perhaps it is worth introducing an educational program on the prevention of injuries in basketball also among coaches working with children and adolescents. It is necessary to develop a unified educational system on the prevention of injuries among young basketball players and on how to proceed when the injury has already occurred.

Limitations and recommendations for future studies

A small number of respondents (after dividing into groups) and the lack of information about training experience of the players were a limitation of this study. In future studies, it would be useful to monitor the incidence of injuries in young basketball players during each tournament as well as in a training period. Such studies should include sports equipment (e.g. type of footwear), type of surface, time and methods of stretching or frequency of using post-exercise recovery (appropriate rest intervals between training sessions/matches and electrotherapy). In addition, it is recommended to monitor injuries among young basketball players depending on the position on the court, as suggested by other authors $[5,10]$. Since preventive measures need to be implemented, it is necessary to know what actions basketball players perform before, during and after training in order to prevent injuries. Moreover, it is fundamental to know what players and coaches do if any injury occurs.

\section{Conclusions}

To sum up, basketball is a contact and injuryprone sport in which players usually sustain lower limb injuries, i.e. ankle injuries, when playing one 
on one (physical contact with a player from the opposite team). The use of stretching exercises and post-exercise recovery strategies (appropriate rest) can be an important factor limiting the occurrence of injuries in young basketball players. Moreover, it is necessary to continue research in this area.

\section{References}

1. Delextrat A, Cohen D. Strength, power, speed, and agility of women basketball players according to playing position. JSCR. 2009;23(7):1974-81.

2. Abdelkrim N, Chaouachi A, Chamari K, Chtara M, Castagna C. Positional role and competitive-level differences in elite-level men's basketball players. JSCR. 2010;24(5):1346-55.

3. Scanlan AT, Tucker PS, Dalbo VJ. A comparison of linear speed, closed-skill agility, and open-skill agility qualities between backcourt and frontcourt adult semiprofessional male basketball players. JSCR. 2014;28(5):1319-27.

4. Drakos MC, Domb B, Starkey C, Callahan L, Allen AA. Injury in the National Basketball Association: a 17-year overview. Sports Health. 2010;2(4):284-90.

5. Meeuwisse WH, Sellmer R, Hagel BE. Rates and risks of injury during intercollegiate basketball. Am J Sports Med. 2003;31(3):379-85.

6. Lewis M. It's a hard-knock life: game load, fatigue, and injury risk in the National Basketball Association. J Athl Training. 2018;53(4):000-000.

7. Meeusen R, Duclos M, Foster C, Fry A, Gleeson M, Nieman D, et al. Prevention, diagnosis and treatment of the overtraining syndrome: Joint consensus statement of the European College of Sport Science (ECSS) and the American College of Sports Medicine (ACSM). EJSS. 2013;45(1):1-24.

8. Pasanen K, Ekola T, Vasankari T, Kannus P, Heinonen A, Kujala UM, et al. High ankle injury rate in adolescent basketball: A 3-year prospective follow-up study. Scand J Med Sci Sports. 2017;27(6):643-9.

9. Ellapen TJ, Narsigan S, Essack FM, Jugroop P, Macrae NA, Milne J, et al. Prevalence of basketball-related musculoskeletal injuries among university players. African Journal for Physical, Health Education, Recreation and Dance. 2012;18(2):308-16.

10. López González L, Rodríguez Costa I, Palacios Cibrián A. Injury incidence rate among amateur basketball players. Revista Internacional de Medicina y Ciencias de la Actividad Física y el Deporte. 2017;17(66):299-316.

11. McKay G, Goldie P, Payne W, Oakes B. Ankle injuries in basketball: injury rate and risk factors. Br J Sports Med. 2001;35(2):103-8.

12. Riva D, Bianchi R, Rocca F, Mamo C. Proprioceptive training and injury prevention in a professional men's basketball team: a six-year prospective study. JSCR. 2016;30(2):461-75.

13. Bijur PE, Trumble A, Harel Y, Overpeck MD, Jones D, Scheidt PC. Sports and recreation injuries in US children and adolescents. Arch Pediatr Adolesc Med. 1995;149(9):1009-16.

14. Randazzo C, Nelson NG, McKenzie LB. Basketball-related injuries in school-aged children and adolescents in $1997-2007$. Pediatrics. 2010;126(4):727-33.

15. McCarthy MM, Voos JE, Nguyen JT, Callahan L, Hannafin JA. Injury profile in elite female basketball athletes at the Women's National Basketball Association Combine. Am J Sports Med. 2013;41(3):645-51.

16. Dick R, Hertel J, Agel J, Grossman J, Marshall S. Descriptive Epidemiology of Collegiate Men's Basketball Injuries: National Collegiate Athletic Association Injury Surveillance System, 1988-1989 Through 2003-2004. J Athl Train. 2007;42(2):194-201.

17. McGuine TA, Brooks A, Hetzel S. The Effect of Lace-up Ankle Braces on Injury Rates in High School Basketball Players. Am J Sports Med. 2011;39(9):1840-8.

18. Bishop JL, Nurse MA, Bey MJ. Do high-top shoes reduce ankle inversion? A dynamic x-ray analysis of aggressive cutting in a high-top and low-top shoe. Footwear Science. 2014;6(1):21-6.

19. Barrett JR, Tanji JL, Drake C, Fuller D, Kawasaki RI, Fenton RM. High- versus low-top shoes for the prevention of ankle sprains in basketball players. A prospective randomized study. Am J Sports Med. 1993;21(4):582-5.

20. Eils E, Schröter RM, Gerss J, Dieter R. Multistation proprioceptive exercise program prevents ankle injuries in basketball. Med Sci Sports Exerc. 2010;42(11):2098-105.

21. Bonato M, Benis R, La Torre A. Neuromuscular training reduces lower limb injuries in elite female basketball players. A cluster randomized controlled trial. Scand J Med Sci Sports. 2018;28(4):1451-60.

22. Meerits T, Bacchieri S, Pääsuke M, Ereline J, Cicchella A, Gapeyeva H. Acute effect of static and dynamic stretching on tone and elasticity of hamstring muscles and on vertical jump performance in track-and-field athletes. Acta Kinesiologiae Universitatis Tartuensis. 2014;20:48-59.

23. Galazoulas C. Acute effects of static and dynamic stretching on the sprint and countermovement jump of basketball players. JPES. 2017;17(1):219-23.

24. Herman K, Barton C, Malliaras P, Morrissey D. The effectiveness of neuromuscular warm-up strategies, that require no additional equipment, for preventing lower limb injuries during sports participation: a systematic review. BMC Med. 2012;10:75. 
25. Witvrouw E, Mahieu N, Danneels L, McNair P. Stretching and injury prevention: an obscure relationship. Sports Medicine. 2004;34(7):443-9.

26. Thacker SB, Gilchrist J, Stroup DF, Kimsey CD Jr. The Impact of Stretching on Sports Injury Risk: A Systematic Review of the Literature. Med Sci Sports Exerc. 2004;36(3):371-8.

27. Gilchrist J, Mandelbaum BR, Melancon H, Ryan GW, Silvers H, Griffin LY, et al. A randomized controlled trial to prevent noncontact anterior cruciate ligament injury in female collegiate soccer players. Am J Sports Med. 2008;36(8):1476-83.

28. Emery CA, Rose MS, McAllister JR, Meeuwisse WH. A prevention strategy to reduce the incidence of injury in high school basketball: a cluster randomized controlled trial. Clin J Sport Med. 2007;17(1):17-24.

29. Hewett TE, Lindenfeld TN, Riccobene JV, Noyes FR. The effect of neuromuscular training on the incidence of knee injury in female athletes. Am J Sports Med. 1999;27(6):699-706.

30. Caparrós T, Alentorn-Geli E, Myer GD, Capdevila L, Samuelsson K, Hamilton B, et al. The relationship of practice exposure and injury rate on game performance and season success in professional male basketball. J Sports Sci Med. 2016;15(3):397-402.

31. FIFA 11+ [internet] Available from: http://stma.cornerkicksystems.com/page/show/717677-the-fifa-11-warm-up-program

32. Mandelbaum BR, Silvers HJ, Watanabe DS, Knarr JF, Thomas SD, Griffin LY, et al. Effectiveness of a Neuromuscular and Proprioceptive Training Program in Preventing the Incidence of Anterior Cruciate Ligament Injuries in Female Athlete. Am J Sports Med. 2005;33(7):1003-10. 